\title{
La "Historia reciente" argentina como forma de Historia actual: emergencia, logros, ¿bloqueos?
}

\section{The Argentina "Recent History" as a Form of Current History: Emergence, Achievements and, Impediments?}

\author{
Luciano Alonso \\ Universidad Nacional del Litoral, Argentina \\ lucalonso@arnet.com.ar
}

\begin{abstract}
Resumen
El presente artículo examina los rasgos, temas y factores políticos y memoriales que giran en torno a lo que en la tradición académica argentina se denomina "historia reciente". Esta es entendida como una forma de referirse a una historia actual, o historia del presente, que se basa en la importancia del pasado traumático procedente del período de la dictadura militar de 1976 a 1983. El autor hace un repaso por los orígenes de ese campo de estudios a partir de la década de 1990, estudia los obstáculos previos, sus tendencias a la interdisciplinariedad y sus resultados más destacados. Asimismo, examina sus limitaciones y las posibles maneras de superarlas, acerca de las cuales plantea la necesidad de recuperar algunas de las preocupaciones que marcaron su nacimiento.
\end{abstract}

\section{Palabras clave}

Historia reciente, Historia actual, Argentina, dimensión ético-política, luchas proderechos humanos.

\begin{abstract}
This article examines the features, topics and political and memory factors which revolve around to which has been called "recent history" in the Argentina academic tradition. This is understood as a form of referring to current history or the history of the present, which is based upon the importance of the traumatic past stemmed from the period of military dictatorship from 1976 to 1983. The author outlines the origins of this field from the 1990s on, studies its early obstacles, its tendencies to interdisciplinarity, and its foremost results. He also examines its constraints and possible ways of solving them, about which he suggests the need to recover some concerns that marked its birth.
\end{abstract}

\section{Key Words}

Recent history, current history, Argentina, ethical and political aspects, struggles for human rights. 


\section{El surgimiento de un nuevo espacio académico y su definición ${ }^{1}$}

En escasos doce o quince años, el estudio del pasado reciente ha adquirido legitimidad académica en los ámbitos historiográficos argentinos. Es notorio que aunque la producción escrita sigue siendo deficitaria -y en este sentido, ¿qué campo de estudios no tiene déficits tanto en Argentina como en tantos otros países semiperiféricos?-, se han roto los límites temáticos y cronológicos que inhibían las preocupaciones, tanto científicas como ético-políticas, que afectaban a multitud de historiadores. Así pues hoy el abordaje de pasados que involucran directamente a las generaciones vivas no parece inconveniente. Por el contrario, y aunque se realiza con el auxilio de muchos sociólogos, políticos, antropólogos y representantes de otras disciplinas, puede decirse que lo que se denomina en Argentina "historia reciente" vive hoy un cierto auge, lo que se refleja en el incremento de las jornadas, mesas temáticas y publicaciones dedicadas a cuestiones encuadrables en ese campo o subcampo así como en la asignación de subsidios y becas de investigación para tal temática.

Quizás la trascendencia de este cambio pueda mesurarse si se tiene en cuenta el punto de fisura que representó la etapa de persecución político-ideológica y de terror de Estado abierta con el gobierno constitucional justicialista de 1973-76, y continuada y profundizada por la última dictadura militar. La depuración en los ámbitos universitarios de los elementos "subversivos", iniciada en 1974, culminó hacia inicios del período dictatorial en el predominio de modelos historiográficos que evitaban aquellas problemáticas de mayor actualidad o referidas a los años más cercanos. Ello no dejaba de ser paradójico frente a la crecida incidencia, cuando no práctica instalación institucional, del presentismo neohegeliano de Antonio Pérez Amuchástegui, lógicamente radicado en un hegelianismo de derechas. Sus obras fueron en cierta medida rectoras en las cátedras introductorias y metodológicas de las carreras de Historia, y divulgaron una concepción centrada en la lectura del pasado a través del prisma del presente, hasta el punto de tornar dificultosa la afirmación de cualquier objetividad. ${ }^{2}$ Precisamente como resguardo frente a la "contaminación" que pudiera sufrir el conocimiento histórico, la "distancia temporal" entre el investigador y los acontecimientos se imponía como norma en el ejercicio de la disciplina.

\footnotetext{
${ }^{1}$ El presente artículo fue escrito en el año 2014 por lo cual, si bien la argumentación general es aún sostenible, deben mencionarse algunas referencias posteriores de importancia. Entre ellas y en función de los planteamientos de este artículo merecen destacarse Marina Franco y Daniel Lvovich, "Historia Reciente: apuntes sobre un campo de investigación en expansión", Boletín del Instituto de Historia Argentina y Americana "Dr. Emilio Ravignani", Tercera serie, 47 (2017): 190-217; Paula Zubillaga, "Los estudios sobre el movimiento de derechos humanos argentino. Un estado de la cuestión", Cambios y Permanencias, 7 (2016) y el dossier "La historia reciente en la Argentina: Problemas de definición y temas de debate", editado por Gabriela Águila y Luciano Alonso en la revista Ayer, 107 (2017).

${ }^{2}$ Especialmente Jorge Luis Casani y A. J. Pérez Amuchástegui, Del "Epos" a la historia cientifica (Buenos Aires: Nova, 1961); A. J. Pérez Amuchástegui, Introducción a la Historia (Buenos Aires: Glauco, 1973) e Id., Algo más sobre la historia (Buenos Aires: Ábaco, 1977).
}

ISSN 2174-4289 
Tal distanciamiento, cifrado según el caso en no menos de treinta o cincuenta años, iba acompañada de un inconfesado repliegue respecto de temáticas tan expurgadas de los ámbitos académicos como los mismos investigadores. Como correlato de la clausura del ciclo de movilización social y política desplegado en Argentina desde la segunda mitad de los años de 1950 a inicios de los de 1970, se clausuró también la posibilidad de desarrollar una historiografía dedicada a los grandes problemas que atravesaban el siglo XX. Al mismo tiempo que muchos historiadores con mayor perfil profesional o político, progresistas o afines a las izquierdas marxistas y peronistas, encontraban refugio en el exilio o en lugares menos expuestos como instituciones de enseñanza media o superior no universitaria, se institucionalizó una narrativa tradicional del pasado "nacional", apoyada por la labor de la Academia Nacional de la Historia y de las correspondientes Juntas o Asociaciones de diversas provincias argentinas. El resultado de esa fractura se pudo apreciar no solo en la decadencia de los estudios históricos sino también en el peso de las investigaciones sobre el pasado colonial y la independencia.

Cabe señalar que el paso de la última dictadura al gobierno constitucional de Raúl Alfonsín (1983-1989) no fue acompañado de un vuelco hacia temas pertenecientes al pasado reciente. Las temáticas de los congresos no variaron sino lentamente, con la inscripción mayoritaria de los trabajos en las matrices de representación del pasado del período anterior y con la predominancia de variados agentes ajenos a la renovación historiográfica e incluso a las propias universidades nacionales. Hasta en los ámbitos académicos más innovadores la historiografía colonial siguió siendo un espacio que concentraba los mayores esfuerzos, aunque claro está que con nuevos enfoques. ${ }^{3} \mathrm{Si}$ bien es cierto que se activaron temáticas antes ocluidas y se ampliaron considerablemente los estudios sobre el siglo XX, la historiografía en su conjunto permaneció distanciada de la documentación, análisis y caracterización de los conflictos de la etapa de movilizaciones populares y violencias estatales que acababa de finalizar. En ese contexto, las preguntas respecto de cómo fue posible la masacre planificada, por qué fracasaron los proyectos revolucionarios, cuáles fueron los apoyos o resistencias al poder dictatorial, o simplemente cómo se fue dando la deriva hacia el ejercicio del terror como disciplinador social, no solo parecían completamente ajenas al universo historiográfico sino directamente impropias de aquel.

\footnotetext{
${ }^{3}$ A modo de ejemplo compárense la continuidad de las narrativas tradicionales sobre la historia argentina en dos congresos regionales como pueden ser el primer y segundo Congreso de Historia de los Pueblos de la Provincia de Santa Fe, de 1982 y 1987, respectivamente (siendo el primero objeto de diversas publicaciones del Gobierno de la Provincia y de la Universidad Nacional del Litoral entre 1984 y 1993 , y permaneciendo sin publicar las ponencias del segundo en el Archivo General de la Provincia de Santa Fe), o las Jornadas Nacionales de Historia del Federalismo: 7 al 11 de octubre de 1986 (Santa Fe, Gobierno de la Provincia, Secretaría de Planeamiento, 1986). A su vez, el predominio de los estudios coloniales en la etapa inicial del actual período constitucional puede apreciarse a través de los índices de ponencias presentadas ante uno de los congreso más innovadores y de funcionamiento más democrático que se pueden evocar: las Jornadas Interescuelas / Departamentos de Historia de Universidades Nacionales, que se realizan desde 1985 con frecuencia bianual.
}

ISSN 2174-4289 
La interpretación presentada por Roberto Pittaluga respecto de esas ausencias es con seguridad la más plausible de todas. Amén de una cierta adecuación a tendencias internacionales, se produjo en Argentina un rechazo a estudiar históricamente el pasado reciente en la década de 1980, por cuanto los principales exponentes de la renovación universitaria se adhirieron a los mitos de la "república perdida" y de la "restauración de la democracia", para lo cual resultaba inconveniente toda interrogación sobre las violencias y proscripciones de las etapas precedentes -más aún cuando correspondían a gobiernos constitucionales-. Por otro lado, en el proceso de legitimación de esos nuevos agentes académicos se construyó una oposición también en gran medida mítica entre una universidad de excelencia supuestamente existente entre 1955 y 1966, y una universidad "politizada" frente al pasado más reciente, que enfatizó la distinción entre historia y política y desplazó la figura del intelectual por la del especialista. En esa dicotomía si bien el trabajo académico se consolidó con sistemas de becas y publicaciones, abandonó todo aquello que pudiera resultar disruptivo o problematizador para la profesionalización en curso. ${ }^{4}$

En esas condiciones, los escasos grupos que en distintas universidades de la zona bonaerense y litoral comenzaron a preocuparse por temas coetáneos no podían menos que ir contracorriente con respecto al consenso imperante. Hasta fecha tan avanzada como 1996 el entonces influyente historiador Luis Alberto Romero llegó a escribir: "La historia termina hace cincuenta años; lo que sigue es política", una definición que en su momento dejaba fuera del análisis historiográfico no solo a la dictadura militar y al período de violencias en el cual se inscribió, sino incluso a los dos primeros gobiernos de Juan Domingo Perón. ${ }^{5}$ La ausencia de investigaciones históricas sobre el pasado reciente era tan notoria, que cuando a finales de los años 90 Fernando Devoto y Marta Madero emprendieron la coordinación de una Historia de la vida privada en Argentina -a semejanza de la que con gran éxito editorial habían dirigido en Francia Phillipe Ariès y George Duby-, el capítulo dedicado a los campos de concentración estuvo a cargo del conocido cineasta y periodista Andrés Di Tella y tuvo un carácter más testimonial que historiográfico. ${ }^{6}$

\footnotetext{
${ }^{4}$ Roberto Pittaluga, "Notas para la historia del pasado reciente", en Jorge Cernadas y Daniel Lvovich (eds.), Historia, ¿para qué? Revisitas a una vieja pregunta (Buenos Aires: Prometeo Libros / Universidad Nacional de General Sarmiento, 2010), 124-130.

${ }^{5}$ Luis Alberto Romero, "Para qué sirve la historia", en el diario Clarín (Buenos Aires), 11 de octubre de 1996. Aún cuando revisó su postura original y aludió en repetidas ocasiones a la ampliación del horizonte de los estudios históricos, Romero no dejó de advertir respecto de lo que considera un problema para el ejercicio del oficio: "Soy historiador de profesión, y cincuenta años me bastan para hacer un balance de la revolución del 16 de setiembre de 1955: sobre sus causas y consecuencias, y sobre las responsabilidades de los actores. Pero soy también un ciudadano que vivió en su infancia el final del peronismo y la Revolución Libertadora, y descubro que cincuenta años no me alcanzan para tomar distancia de las fuertes vivencias de entonces, formadas en un hogar de opositores y en una escuela primaria peronista, con la Marcha y con 'Evita me ama"” (Luis Alberto Romero, "16 de septiembre de 1955. Un balance", en Clarín, 13 de septiembre de 2005).

${ }^{6}$ Andrés Di Tella, "La vida privada en los campos de concentración", en Fernando Devoto y Marta Madero, Historia de la vida privada en la Argentina. Tomo III. La Argentina entre multitudes y soledades. De los años treinta a la actualidad (Buenos Aires: Taurus, 2006 [ $1^{\text {a }}$ Ed. de 1999]). Otro texto del mismo volumen que toca un tema que hoy sería considerado de "historia reciente", como es ISSN 2174-4289 
Sin embargo, la emergencia de la historia reciente comenzó a cuajar prontamente para esas fechas. Por un lado, la producción sobre el pasado reciente de sociólogos y politólogos comenzó a resultar cada vez más difícil de ignorar y fue conformando un espacio de debates atractivo para distintos historiadores. En segundo lugar, el impacto internacional de los Genocide Studies ofreció nuevas miradas sobre el período de terror estatal, renovando las posibilidades de asimilarlo o diferenciarlo de otras experiencias de exterminio masivo o selectivo. Por último, la coyuntura político-social no fue menos importante a la hora de impulsar el interés de los académicos, en un momento además en el cual amplios sectores de la intelectualidad se oponían a las políticas neoliberales del peronista Carlos Saúl Menem -filiadas con mayor o menor acierto con las de la dictadura-. Asimismo, en este periodo las memorias sociales sobre la represión adquirían un nuevo ímpetu con el movimiento de derechos humanos y los "Juicios de Madrid”, instruidos por Baltasar Garzón, contra represores argentinos y chilenos.

Casi en paralelo y poco más adelante, serían de gran trascendencia las interacciones con grupos de investigación e instituciones españolas que aportaban nuevas miradas, como la "historia inmediata" propugnada por Historia a Debate, la "historia del presente" en la formulación de Julio Aróstegui o la misma Asociación de Historia Actual, gestada en el cruce de siglos a partir de contactos internacionales. No solo nuevos investigadores se plegaron a la tendencia creciente, sino que otros ya formados comenzaron a indagar sobre temas de mayor trascendencia para el mundo actual o incluso retomaron cuestiones temporalmente abandonadas. ${ }^{7}$

Para mediados de la primera década del siglo XXI, era patente que un conjunto de autores y textos se inscribían en nuevas preocupaciones sobre el pasado más inmediato y se distinguían por un corte temporal de los contemporaneístas. ${ }^{8}$ De acuerdo con Gabriela Águila, se superó una etapa en la cual las memorias y la oralidad eran el eje de la reflexión sobre ese tiempo pasado, abriéndose una parcela en el estudio histórico dedicada al estudio de las décadas más cercanas. Tal y como sostiene la autora, en este momento surgieron ya con pleno reconocimiento una historia y una historiografía del

\footnotetext{
“Televisión y vida privada", había sido escrito por Gonzalo Aguilar, titulado en Letras y especialista en literatura.

${ }^{7}$ Es sintomático que una colonialista como Nidia Areces retomara durante estos años sus preocupaciones por la historia más reciente, "congeladas" por la persecución política, y las abordara en perspectiva comparada. Véase Nidia Areces, "Las fuerzas armadas en la transición a la democracia. Argentina y España, dos procesos: semejanzas y diferencias", Historia Regional, 17 (1999 [artículo escrito originariamente en 1997]).

8 A partir de aquí alterno las referencias a esos historiadores en la tercera persona del plural, con ocasionales referencias en las que me incluyo utilizando la primera persona del singular o del plural. Procedo así en consideración tanto hacia aquellas cuestiones generales de las cuales me siento un tanto alejado, como frente a otras más precisas que me incumben. Asimismo, este proceder también refleja una suerte de incomodidad con la definición de lo que supuestamente supondría ser "historiador", término sustancialmente correcto pero casi asociado a una condición masculina, profesional y elitista con la cual no querría ver definido mi espacio laboral, siendo además poco sensible de cara a mis titulaciones, desempeños y preocupaciones en historia y sociología, que espero sirvan para superar delimitaciones a veces absurdas.
}

ISSN 2174-4289 
pasado reciente, distinguible de lo producido por otras ciencias sociales y otras narrativas, aunque los aportes procedentes de otras matrices disciplinares siguieron nutriendo ese ámbito de estudios. ${ }^{9}$

En 2007, un texto colectivo compilado por Marina Franco y Florencia Levín puso en evidencia no solo la intención de obtener el reconocimiento de un campo académico, sino también la complejidad de problemas de diversa índole que rodeaban su definición. Afirmando una relación entre la historia reciente y la existencia de momentos traumáticos, la frase inicial de la introducción a Historia reciente. Perspectivas y desafíos de un campo en construcción establecía una identificación tajante: "La historia de la historia reciente es hija del dolor". Los acontecimientos traumáticos o de fuerte presencia social en el presente son los objetos privilegiados que en esa lectura pueden marcar cesuras temporales a partir de las cuales pensar la historia reciente:

Si bien no existen razones de orden epistemológico o metodológico para que la historia reciente deba quedar circunscripta a acontecimientos de ese tipo -decían-, lo cierto es que en la práctica profesional que se desarrolla en países como la Argentina y el resto del Cono Sur, que han atravesado regímenes represivos de una violencia inédita, el carácter traumático de ese pasado suele intervenir en la delimitación del campo de estudios.

Es ese "pasado que no pasa" el que impone entonces una temporalidad de fuertes connotaciones políticas a una práctica historiográfica específica. ${ }^{10}$

Esa delimitación -que personalmente no considero incorrecta pero sí insuficiente, como desarrollaré en comentarios posteriores- llegó a imponerse sin mucha discusión en el ámbito académico. De alguna manera, el debate conceptual sobre la forma de denominar a esa tendencia se pasó por alto en Argentina, asumiéndose directamente dicha definición sin considerar la mayor o menor pertinencia de otros términos como historia actual, historia inmediata, historia del presente o del tiempo presente, historia en curso o similares. Aunque en ocasiones podría suponerse una superposición de intereses y recortes temporales, en rigor la "historia reciente" construida a partir de esos problemas no alcanzó a involucrar la multitud de dimensiones sociales que se incluyen en otras definiciones. Entonces esta formulación argentina aparece en rigor como una forma específica o sector especializado de historia actual o historia del presente, vinculada a un pasado traumático por más que su denominación pueda sugerir un mero recorte cronológico.

\section{Hibridaciones disciplinares y desarrollos en curso}

\footnotetext{
${ }^{9}$ Gabriela Águila, "La Historia Reciente en la Argentina: un balance”, Historiografías, revista de historia y teoría, 3 (2012): 62-76. Recuperado de: http://www.unizar.es/historiografias [consulta 28 junio, 2018].

${ }^{10}$ Marina Franco y Florencia Levín (comps.), Historia reciente. Perspectivas y desafios de un campo en construcción (Buenos Aires: Paidós, 2007), 16 y 34. Un análisis de ese texto y la discusión de algunas de las dimensiones conceptuales, que incluyen la postulación de la historia reciente como una especialidad o subdisciplina y no como un campo, en Luciano Alonso, "Sobre la existencia de la historia reciente como disciplina académica. Reflexiones en torno a Historia reciente. Perspectivas y desafíos de un campo en construcción", en Marina Franco y Florencia Levín (comps.), Prohistoria. Historia - Políticas de la Historia, 11 (2007): 191-204.
}

ISSN 2174-4289 
Los modos de hacer historia reciente son hoy en Argentina tan múltiples como los relativos a cualquier otra historiografía sectorial o especialidad. Con la participación plena de sociólogos, economistas y otros científicos sociales, los historiadores abordan las principales temáticas con teorías y métodos muy variados. Las políticas de memoria, las representaciones del pasado, el papel de los intelectuales, las políticas estatales, las transformaciones estructurales, las actitudes sociales, los movimientos sociales y las organizaciones políticas o guerrilleras, han sido cuestiones cada vez más abordadas por un abanico plural de profesionales, guiados más allá de su formación disciplinar por una intención de comprensión en la dimensión diacrónica que caracteriza a la historia como ciencia. $^{11}$

Una revisión exhaustiva de esa producción resultaría muy extensa aquí, por lo que prefiero remitirme a los excelentes balances provisionales que se han hecho en torno a la represión y el movimiento obrero en Argentina. ${ }^{12}$ Merece la pena destacar, eso sí, algunos problemas que podemos identificar como "típicos" de la historia reciente argentina, como demostración puntual de esa vitalidad y, al mismo tiempo, de sus tensiones, para luego ver en un ejemplo más detallado las formas de construcción de una historia actual entre la "transición democrática" y la actualidad.

Este repaso no puede sino comenzar por una temática que para la historiografía sobre el pasado reciente resulta central. Me refiero al estudio de la represión y de la aplicación de las técnicas de tortura y de desaparición forzada de los opositores. Las formas generales del método represivo fueron tempranamente identificadas por el sociólogo Juan Corradi y analizadas en sus múltiples facetas por la politóloga Pilar Calveiro -ambos radicados en instituciones del exterior-, siendo sus aportes imprescindibles para una historización de la represión. ${ }^{13}$ Al tiempo, correspondió a

\footnotetext{
${ }^{11}$ María Paula González ha destacado que: "Como campo de estudios y narrativas, la historia reciente es un ámbito paradojal. De una parte, el espacio historiográfico argentino ha expresado fuertes resistencias a abordarlo. De otra, es un campo abonado por aportaciones de la sociología, la economía, las ciencias políticas, el periodismo, el cine, la literatura testimonial, etc. El resultado es ambiguo: por un lado impera una relativa ausencia de investigaciones sistemáticas por parte de los historiadores (más allá de la historia de la memoria) y, por otro, existe una extensa producción de otras narrativas y estudios sociales". Véase: "La historia argentina reciente en la escuela media: un inventario de preguntas", Entrepasados, 28 (2005): 83-100 (85).

12 Véase Gabriela Águila, "La represión en la historia reciente argentina: perspectivas de abordaje, conceptualizaciones y matrices explicativas", Contenciosa, 1 (2013). Recuperado de: http://www.bibliotecavirtual.unl.edu.ar/ojs/index.php/Contenciosa/article/view/5043/7680 [consulta 28 de junio, 2018]; y Andrés Carminati, “Algo habrán hecho'. La historia de los trabajadores durante la última dictadura militar (1976-1983). Un repaso historiográfico”, Historia Regional, 30 (2012): 13-34. Aquí es inevitable ampliar el repaso de Carninati a la edición de un libro posterior, de principal importancia por su enfoque metodológico y su efecto de demostración de las consecuencias del terror de Estado sobre el movimiento obrero. Me refiero al trabajo de Federico Lorenz, Algo parecido a la felicidad. Una historia de la clase trabajadora durante la década del setenta (1973-1978) (Buenos Aires: Edhasa, 2013).

${ }^{13}$ Juan Corradi, "El método de destrucción. El terror en la Argentina”, en Hugo Quiroga y César Tcach (comps.), A veinte años del golpe. Con memoria democrática (Rosario: Homo Sapiens, 1996 [1 ${ }^{\mathrm{a}}$ Ed. de 1983]), 89; Pilar Calveiro, Poder y desaparición. Los campos de concentración en Argentina (Buenos Aires: Colihue, 1998).
}

ISSN 2174-4289 
comisiones investigadoras especiales ${ }^{14}$ y a las instituciones judiciales realizar una pormenorizada recopilación y producción de fuentes, en función de las transformaciones en la estructura de oportunidades políticas y las sucesivas fases de enjuiciamiento o impunidad. ${ }^{15}$ En los últimos tiempos, la confluencia entre agentes académicos y judiciales ha alcanzado una mayor trascendencia. ${ }^{16}$

Las definiciones y descripciones que se produjeron en esos ámbitos parecieron agotar esta misma temática. Sin embargo ni las visiones globales, como la ofrecida por la CONADEP, ni las puntuales, como aquellas otras presentadas por los distintos juicios aún en curso, permitieron esto. Por ejemplo, ni siquiera hay un acuerdo generalizado respecto al número de víctimas de desaparición forzada o asesinadas en enfrentamientos simulados. ${ }^{17}$ Además, a pesar de la referencia constante a nociones como la de "dispositivo" y a la importancia del análisis factual en textos como los de Calveiro, en esos acercamientos al pasado reciente primó en general un camino desde categorías definidas a la realidad empírica: precisado el contenido de un concepto, se veía luego la adecuación de los registros empíricos al mismo -en el caso de los juicios, partiendo de la definición del crimen se apreciaba su existencia en los actos objeto de testimonios-. Por último, las narrativas globalizantes sobre la represión no dejaron ver sus

${ }^{14}$ Debe recordarse que además de la conocida CONADEP (Comisión Nacional sobre la Desaparición de Personas), funcionaron en Argentina una Comisión Permanente de Derechos Humanos en el ámbito de la Cámara de Diputados de la Provincia del Chaco, así como una Comisión Bicameral investigadora en la Provincia de Tucumán.

15 Grosso modo pueden identificarse tres períodos, fuertemente condicionados por las distintas correlaciones de fuerza entre el gobierno nacional, la corporación militar, la justicia federal y los movimientos sociales, muy especialmente el de derechos humanos. Una primera etapa hacia 1983-1985, caracterizada por las discusiones sobre los alcances de la revisión del pasado que incluyeron la actividad de las comisiones especiales, la apuesta del gobierno nacional por un proceso judicial limitado y el Juicio a las Juntas Militares. Un segundo período de progresiva implantación de la impunidad, marcado por la promulgación de leyes exculpatorias e indultos, que comenzó en el gobierno radical hacia 1987 y se extendió por todo el gobierno menemista de 1989-1999, teniendo como correlato la persecución penal ante tribunales de España, Italia y Francia y la realización de "juicios por la verdad" en Argentina -sin valor penal pero sí informativo-. Por fin una tercera etapa tibiamente abierta con las declaraciones de inconstitucionalidad de las medidas de impunidad en sede judicial y con la instrucción del radical Fernando de la Rúa a la Procuraduría General, con el fin de que revisara las posibilidades de procesamiento judicial en Argentina, que con el gobierno justicialista de Néstor Kirchner avanzó decididamente en el desarrollo de políticas de memorias y justicia, promoviéndose el encausamiento y condena de numerosos represores.

${ }^{16}$ Véase Luciano Alonso, "La definición de las ofensas en el movimiento por los derechos humanos en Argentina y la calificación de 'genocidio",, Contenciosa, 1 (2013). Recuperado de: http://bibliotecavirtual.unl.edu.ar/ojs/index.php/Contenciosa/article/view/5044/7685 [consulta 28 junio, 2018].

${ }^{17}$ A modo de rápido ejemplo cabe destacar que el informe de la CONADEP recogió poco menos de 9.000 denuncias de desaparición forzada, mientras que para 2003 la Secretaría de Derechos Humanos de la Nación ya disponía de un registro actualizado de 13.000 desapariciones. Amnistía Internacional estimó la cifra en 15.000 casos, en tanto que los informes de la DINA chilena indicaban que el área de inteligencia del Ejército Argentino había computado para julio de 1978 hasta 22.000 opositores eliminados. Los organismos de derechos humanos defienden aún la cifra emblemática de 30.000, que no tiene razón de ser historiográfica sino más bien política. Debe también asumirse como factible que entre los sectores populares y marginales se hayan producido desapariciones y asesinatos no denunciados, $\mathrm{u}$ otros hechos no considerados en su momento como acciones represivas, y todavía hoy escasamente estudiados.

ISSN 2174-4289 
inscripciones locales, la diversidad de agentes y de violencias, o incluso uniformizaron las actitudes frente a ellas, creando imágenes excesivamente simplificadas de resistentes y colaboradores. Asumida la Escuela de Mecánica de la Armada como modelo de campo de concentración, tortura y exterminio ("campo de desaparición" en la precisa definición de Martyniuk) ${ }^{18}$, quedaba poco lugar para comprender las muchas modalidades y el grado de indeterminación que el plan de exterminio dejaba a voluntad de las unidades operativas.

En los últimos años comenzaron a producirse una serie de estudios localizados que demostraron la amplitud de las diferenciaciones que se registraron en la materia. Con el trabajo de Gabriela Águila sobre la represión en la zona del gran Rosario, se evidenció la posibilidad de identificar amplias variaciones regionales, que afectaban no solo a las técnicas puntuales aplicadas sino además a la integración o no de las fuerzas policiales, a diferencias en la escala, articulación y funcionamiento de los centros de detención y a las políticas de exhibición limitada del terror, que aseguraba el efecto paralizante sobre los disidentes. ${ }^{19}$ Hoy sigue existiendo un gran vacío en la materia, pero investigadores como Ana Belén Zapata, Yolanda Urquiza, Mónica Gatica y Pablo Scatizza están desarrollando trabajos sobre localizaciones muy variadas del interior argentino, que arrojan nueva luz sobre los dispositivos represivos. ${ }^{20}$ También se han ido investigando los dispositivos carcelarios, sublimados en anteriores momentos por la trascendencia y predominio de la figura del detenido-desaparecido, así como de los centros clandestinos de detención. ${ }^{21}$

Por su parte, Marina Franco ha realizado un aporte de singular trascendencia, mostrando el modo en el cual la noción de "subversión" se instaló en un proceso que atravesó tanto gobiernos constitucionales como dictatoriales. Abordando con detalle y profundidad aspectos centrales del período de gobierno justicialista de 1973-1976, su planteamiento se inscribe en una serie de aportes historiográficos que relativizan cada vez más la idea de un corte abrupto producido por el golpe de Estado del 24 de marzo de 1976, y que por el contrario presentan interpretaciones más complejas, en las cuales

\footnotetext{
${ }^{18}$ Claudio Martyniuk, ESMA. Fenomenología de la desaparición (Buenos Aires: Prometeo, 2004), 13 y ss.

${ }_{19}$ Gabriela Águila, Dictadura, represión y sociedad en Rosario, 1976/1983. Un estudio sobre la represión y los comportamientos sociales en dictadura (Buenos Aires: Prometeo, 2008).

${ }^{20}$ Ana Belén Zapata, "Violencia parapolicial en Bahía Blanca, 1974-1976. Delgados límites entre lo institucional y lo ilegal en la lucha contra la "subversión apátrida", Anos 90, 19 (2012): 111-140; Yolanda Urquiza, Misiones bajo el terror. 1976-1983. Haciendo historia de la dictadura cívico-militar (Argentina: Universidad Nacional de Misiones, 2010); Mónica Gatica, "Develando complicidades: la temprana colaboración entre los aparatos represivos de Chile y Argentina. Chubut, 1973", Archivos. Boletín de la Biblioteca Rafael Galván, 2 (2013): 39-62; Pablo Scatizza, “Campos de concentración y centros de clandestinos de detención como elementos constitutivos del dispositivo represor. La dictadura en Norpatagonia", ponencia presentada ante las XIV Jornadas Interescuelas - Departamentos de Historia, Mendoza, del 2 al 5 de octubre de 2013.

${ }^{21}$ Santiago Garaño y Werner Pertot, Detenidos-aparecidos. Presas y presos políticos de Trelew a la dictadura (Buenos Aires: Biblos, 2007); Silvina Merenson y Santiago Garaño (coords.), La prisión política en la Argentina, entre la historia y la memoria (1966-1983), dossier en Revista Iberoamericana, 40 (2010).
}

ISSN 2174-4289 
se articulan cambios y continuidades en las prácticas estatales y en los discursos dominantes; todo ello para demostrar el modo en el cual se fue desarrollando una espiral de aniquilamiento. ${ }^{22}$

Donde el enfoque de Franco parece menos sólido es precisamente en un aspecto que no constituye el eje central de su libro y que en gran medida elude, pese a ser sustancial para su explicación de esa espiral ascendente, cuál es el funcionamiento -y la responsabilidad- de las agrupaciones político-militares. En ese sentido y aún a riesgo de resultar injusto en el olvido de aportes historiográficos mucho más tempranos, entre los que cabe destacar los de Pablo Pozzi, conviene apreciar los enfoques de dos textos de suma importancia que marcan modos diferentes de comprender no solo esos agrupamientos sino la misma historia como disciplina: Los combatientes de Vera Carnovale y Los montoneros del barrio de Javier Salcedo. El texto de Carnovale, dedicado al estudio del Partido Revolucionario de los Trabajadores / Ejército Revolucionario del Pueblo, se basa en un minucioso análisis discursivo para negar la tesis de la "militarización" de las organizaciones político-militares y postular a su vez que su trayectoria estuvo determinada por la fidelidad a sus ideas o construcciones imaginarias. Partiendo de los manifiestos partidarios a la moral y las reglas de conducta, Carnovale llega a la postulación de una ética sacrificial que estaría en la base de las concepciones de esa agrupación. Por el contrario, Salcedo analiza a través de un estudio focalizado en un distrito del Gran Buenos Aires la principal organización políticomilitar peronista. Su propósito es mostrar cómo el complejo entramado de actores y relaciones sociales marca la deriva de la agrupación de un modo completamente distinto al postulado en textos clásicos, descubriendo todo tipo de tensiones políticas, culturales y de clase social. ${ }^{23}$ Esos dos ejemplos son ilustrativos de caminos muy diferentes: una mirada global y centrada en el universo discursivo en un caso, y un enfoque particular y centrado en las prácticas en el otro.

Por último, el tema del exilio ha sido uno de los más disruptivos al acompañar el desarrollo de las memorias sociales orientadas a romper de lleno el tabú respecto de quienes eligieron abandonar el país durante el período de terror de Estado. Otra vez Marina Franco ha sido una de las más importantes voces en la construcción de ese objeto de estudio, articulando el análisis del fenómeno del exilio argentino en Francia con la consideración de las acciones llevadas a cabo por los exiliados en denuncia de los crímenes dictatoriales. Otro tanto han hecho, con igual profundidad, Silvina Jensen para el caso de Cataluña y Pablo Yankelevich para México. Hoy se articulan en torno a sus propuestas multitud de estudios particulares que incluyen problemas de definición, cuestiones relacionadas con las acciones políticas, el retorno de los exiliados y la segunda generación transterrada, y las políticas estatales de asilo, refugio y destierro,

\footnotetext{
22 Marina Franco, Un enemigo para la nación. Orden interno, violencia y “subversión”, 1973-1976 (Buenos Aires: Fondo de Cultura Económica, 2012).

${ }^{23}$ Vera Carnovale, Los combatientes. Historia del PRT-ERP (Buenos Aires: Siglo XXI, 2011); y Javier Salcedo, Los montoneros del barrio (Buenos Aires: Eduntref, 2011). Debo esta comparación a Andrea Raina, becaria de posgrado de CONICET, que ha publicado una reseña del segundo texto en la revista digital Rey Desnudo, 2 (2013). Recuperado de: https://reydesnudo.com.ar/reydesnudo/article/viewFile/53/53 [consulta 28 junio, 2018].
}

ISSN 2174-4289 
temas todos ellos integrados en unas jornadas específicas que se proyectan a los casos del Cono Sur. Pero el gran desafío ha sido planteado por Yankelevich en el sentido de realizar estudios cuantitativos sobre una materia que ha girado siempre en torno a las estimaciones más amplias posibles. $^{24}$

Resulta oportuno ahora estudiar con más detalle un caso particular para apreciar el modo en el cual fue delimitándose una temática como es el estudio de las luchas pro derechos humanos, ya que de alguna manera es ilustrativo tanto de la ausencia inicial de investigadores formados en la disciplina histórica como de los problemas y tendencias característicos de la historia reciente.

\section{A modo de demostración: la historización de las luchas pro derechos humanos}

Desde la década de 1980 fueron produciéndose aportes plurales que convalidaron en ámbitos periodísticos y académicos la noción de conformación de un movimiento social en defensa de los derechos humanos violados durante el período de terror de Estado. En el segundo campo se privilegió la definición de un espacio discursivo compartido, que buscaba diferenciar a unos agentes colectivos asociados a partidos políticos de otros más autónomos, en pro de su legitimación en algo más básico y trascendente que la lucha política -que se identificó prontamente con la lucha por la vigencia de derechos humanos fundamentales-.

En principio la denominación usual fue la de "organismos" u "organizaciones de derechos humanos", identificación compartida por los mismos agentes colectivos sugerida en el trabajo de Raúl Veiga, pero prontamente combinada con la definición en términos de la entonces creciente literatura sobre los "movimientos sociales" en los aportes de Leis, Brysk, Jelin y Sondereguer, todos ellos sociólogos y politólogos. ${ }^{25}$

\footnotetext{
${ }^{24}$ Véase Marina Franco, El exilio. Argentinos en Francia durante la dictadura (Buenos Aires: Siglo XXI, 2008); Silvina Jensen, La provincia flotante. El exilio argentino en Cataluña (1976-2006) (Barcelona: Fundació Casa Amèrica Catalunya, 2007); e Id., Los exilados. La lucha por los derechos humanos durante la dictadura (Buenos Aires: Sudamericana, 2010); Pablo Yankelevich, Ráfagas de un exilio. Argentinos en México, 1974-1983 (Buenos Aires: Fondo de Cultura Económica, 2010).

${ }^{25}$ Raúl Veiga, Las organizaciones de derechos humanos (Buenos Aires: Centro Editor de América Latina, 1985); María Sondereguer, "Aparición con vida. El movimiento de derechos humanos en Argentina”, en Elizabeth Jelin (ed.), Los nuevos movimientos sociales. Vol. 2 (Buenos Aires: Centro Editor de América Latina, 1985); Héctor Ricardo Leis, El movimiento por los derechos humanos y la política argentina (Buenos Aires: Centro Editor de América Latina, 1989); Alison Brysk, La política de derechos humanos en Argentina. Protesta, cambio y democratización, traducción de The Politics of Human Rights in Argentina: Protest, Change, and Democratization (Stanford: Stanford University Press, 1994). Más tarde Elizabeth Jelin, "La política de la memoria: el Movimiento de Derechos Humanos y la construcción democrática en la Argentina", en Carlos H. Acuña y otros, Juicio, castigos y memorias. Derechos humanos y justicia en la política argentina (Buenos Aires: Nueva Visión, 1995); e Id., "Los derechos humanos entre el Estado y la sociedad", en Juan Suriano (dir.), Nueva historia Argentina. Dictadura y democracia, 1976-2001 (Buenos Aires: Sudamericana, 2005).
}

ISSN 2174-4289 
Chama y Sorgentini han resumido ese enfoque, asimilándolo a su vez a una primera forma de preocupación por el problema de la memoria del pasado reciente argentino:

Tomando como referencia teórica el modelo de los "nuevos movimientos sociales", las ciencias sociales subrayaron la "novedad" de este movimiento, así como la expectativa "positiva" que despertaba su potencial capacidad de abrir nuevas y más intensas formas de participación política y, sobre todo, social. ${ }^{26}$

Así, el modelo de derivación del concepto a la realidad empírica se cumplió en cierta manera, cargándose además de expectativas la acción de agentes que se entendían autónomos y con posiciones universalistas. Ello implicó el establecimiento de una lista de ocho organismos como componentes del movimiento, emergentes del período 19741980: el Servicio Paz y Justicia (SERPAJ); la Asamblea Permanente por los Derechos Humanos (APDH); el Movimiento Ecuménico por los Derechos Humanos (MEDH); Familiares de Detenidos y Desaparecidos por Razones Políticas y Gremiales; Madres de Plaza de Mayo; Abuelas de Plaza de Mayo y el Centro de Estudios Legales y Sociales (CELS), enumeración a la que se suma la preexistente Liga Argentina por los Derechos del Hombre (LADH), cuya constitución se remonta a 1937. En algunos casos se incluyó al frecuentemente olvidado Movimiento Judío por los Derechos Humanos, como alternativa a la confesionalidad cristiana del MEDH. ${ }^{27}$

Todas esas agrupaciones se formaron en la ciudad de Buenos Aires y registran acciones continuas desde su aparición hasta la actualidad, pero no se replicaron sin más ni en el interior ni en el exterior del Estado nacional. Sobre ellas se ha formado desde mediados de los años de 1980 una narrativa "clásica" -en el sentido de "típica o característica"-, que describe a grandes rasgos la formación de un agente colectivo. En ese proceso se construyó el objeto "movimiento por los derechos humanos", postulando su localización "en Argentina" (aun cuando su contenido empírico refiriese casi en exclusiva a la Capital Federal).

Tal lista se construyó sin revisar la existencia de esos organismos en el interior del país o identificar variaciones, y mayormente sin alusiones a su posible articulación internacional. El elemento privilegiado para definir a esas agrupaciones como algo distinto de las anteriores fue la tipificación de un "lenguaje de los derechos humanos" de corte universalista, que proclamaría el resguardo de toda vida más allá de la pertenencia a una determinada familia política. Se identificó más tarde un "mito de la inocencia" en el tránsito de la dictadura al orden constitucional, como estrategia defensora conducente a ocultar o negar el carácter de militantes de los detenidos-

\footnotetext{
${ }^{26}$ Mauricio Chama y Hernán Sorgentini, "Momentos, tendencias e interrogantes de la producción académica sobre la memoria del pasado reciente argentino", Nuevo Mundo Mundos Nuevos, noviembre de 2011. Recuperado de: https://journals.openedition.org/nuevomundo/62176 [consulta 28 junio, 2018].

${ }^{27}$ Elizabeth Jelin y Pablo de Azcárate, "Memoria y política: movimientos de derechos humanos y construcción democrática", América Latina Hoy, 1 (1991): 29-38 (31).

ISSN 2174-4289 
desaparecidos, para evitar así la deslegitimación del reclamo, que se postuló también general. $^{28}$

Varios de esos textos tuvieron el indudable mérito de presentar un panorama completo de la situación capitalina y de registrar las diferencias de criterios o los conflictos entre distintas organizaciones. Inversamente, se tendió a minimizar una característica central de los procesos de movilización, como es la derivación de elementos discursivos y formatos de organización y acción -cuando no de personas- de las experiencias previas a las más recientes. Se produjo con el tiempo una focalización parcial sobre lo que a todas luces era el componente más novedoso del movimiento: las Madres de Plaza de Mayo. Los estudios sobre esa agrupación hicieron hincapié en la condición de género, en el paso de la preocupación individual a la definición política y en la resignificación de la maternidad. ${ }^{29}$ A partir de esos desarrollos fueron posibles nuevos estudios, que se complejizaron con la formación de H.I.J.O.S. (Hijos por la Identidad y la Justicia contra el Olvido y el Silencio), incorporando otra variable generacional y descubriendo nuevas dimensiones de la cultura política.

En último lugar, el paso de los organismos de derechos humanos de la preocupación exclusiva por la vida y la integridad física de las víctimas del terror de Estado a una agenda progresivamente ampliada fue objeto de diversas interpretaciones, entre las que descolló la idea -sostenida también en ámbitos político-partidarios-según la cual eso suponía un desvío de los objetivos del movimiento social cuando no de su pureza original. ${ }^{30}$ De la misma manera, más cercanamente se señaló esa ampliación de agenda de modo positivo cuando fue acorde a las opciones políticas de los investigadores, tratando siempre de defender la idea de que la misma asociación con las agencias estatales no lesionaba la autonomía del movimiento social. ${ }^{31}$

Podría aducirse que estos ejemplos nos ubicarían lejos de la "narrativa clásica", pero se da la peculiaridad de que no solamente todos comparten facetas de ese enfoque que se detallan a continuación, sino que aún en casos como los de Mercedes Barros y Virginia Morales -investigadoras radicadas en la provincia de Córdoba- el objeto privilegiado del análisis sigue siendo el discurso de las agrupaciones capitalinas. Cambian las opciones ético-políticas de los investigadores y los elementos discretos bajo análisis, pero la matriz fundamental no se transforma.

Tal vez esta evolución muestra las ramificaciones de una narrativa académica y hacen a veces abusiva su presentación simplificada. Pero es innegable que esas

\footnotetext{
${ }^{28}$ Véase Marcos Novaro y Vicente Palermo, La dictadura militar, 1976/1983. Del golpe de Estado a la restauración democrática (Buenos Aires: Paidós, 2003).

${ }^{29}$ Véase Marysa Navarro, "Lo personal es político. Las Madres de Plaza de Mayo", en Susan Eckstein (coord.), Poder y protesta popular. Movimientos sociales latinoamericanos (México: Siglo XXI, 2001); María Virginia Morales, De la cocina a la plaza. La categoría "madre" en el discurso de las madres de Plaza de Mayo (Villa María: EDUVIM, 2010).

${ }^{30} \mathrm{H}$. R. Leis, El movimiento por los derechos humanos.

${ }^{31}$ María Virginia Morales, "Asociación Madres de Plaza de Mayo: kirchnerismo y resignificación”, en M. Barros, A. Daín y V. Morales (comps.), Escritos K (Villa María: EDUVIM, 2012).
}

ISSN 2174-4289 
reconstrucciones intelectuales conformaron una visión típica y característica del agente colectivo, basada en la hipertrofia de algunos elementos. Sus efectos aún se encuentran presentes en muchos estudios de caso. La narrativa clásica traspuso la realidad $-\mathrm{O}$ incluso parte de la realidad- de una zona específica como Buenos Aires a la Argentina en su conjunto. En términos de una nueva camada de investigadores atentos a las diferencias que pueden plantearse desde los casos locales, la mayor parte de los discursos disciplinares son aún "porteño-céntricos". ${ }^{32}$ Establecida una historia prototípica en la zona bonaerense, los casos locales aparecen ante todo como réplica de lo definido previamente como estatal/nacional, o incluso revestidos de un cierto exotismo.

Por otra parte, el establecimiento de la lista de ocho organismos adquirió características canónicas e incluso quienes trataron de reflejar la complejidad de esas acciones no pudieron escapar a considerarla invariante. ${ }^{33}$ Eso ha hecho prácticamente imposible pensar como parte del movimiento social a una miríada de grupos de diversa naturaleza que actuaron en plena dictadura, como son entidades tan distintas como Madres de Detenidos-Desaparecidos de Tucumán o el Centro "Testimonio" de la ciudad de Rafaela, en la provincia de Santa Fe. Se ha desplazado también el papel de espacios de debate y acción de suma importancia, como los Foros o Asambleas contra la impunidad, constituidos hacia la primera mitad de la década de 1990 en distintas localizaciones del interior y con gran repercusión. Adicionalmente, ha dificultado la consideración de agrupaciones constituidas fuera de los límites del Estado nacional, tanto en territorios latinoamericanos como europeos. Agrupaciones que solo después fueron abordadas por los investigadores dedicados a la problemática del exilio, y entre las cuales pueden destacar la Comisión de Solidaridad con Familiares de Desaparecidos en Argentina (COSOFAM), el Comité de Solidaridad con el Pueblo Argentino (COSPA) o la Comisión Argentina por los Derechos Humanos (CADHU), que a pesar de sus orígenes en estructuras partidarias se fueron plegando a la nueva narrativa humanitaria.

En tercer lugar, la narrativa clásica ha planteado como válidos para el movimiento en su conjunto elementos que en realidad operaron de forma polifacética. Por ejemplo, la afirmación de la noción de "víctima inocente" como un tópico extendido, que recién se revertiría con una re-politización de la memoria y un nuevo discurso sobre la militancia hacia mediados de la década de 1990, cuando hay ejemplos muy tempranos de ensalzamiento de las opciones políticas de los desaparecidos. O la idea de una

\footnotetext{
${ }^{32}$ La expresión entrecomillada pertenece a Silvina Jensen, "Diálogos entre la historia local y la historia reciente en Argentina. Bahía Blanca durante la última dictadura militar", en el Congreso Internacional 1810-2010: 200 años de Iberoamérica (Santiago de Compostela, XIV Encuentro de Latinoamericanistas Españoles, 2010), 1427.

${ }^{33}$ Es por ejemplo el caso de Ulises Gorini (Historia de las Madres de Plaza de Mayo. Tomo II La otra lucha (1983-1986) [Buenos Aires: Norma, 2007], 154-155), quien una página después de registrar la creación de la Asociación de Ex Detenidos Desaparecidos y considerarla parte del movimiento de derechos humanos, vuelve a hablar de "los ocho organismos" con total naturalidad. Sería extensa la enumeración de los múltiples trabajos que aún hoy insisten en esa perspectiva, agregándose a H.I.J.O.S. desde mediados de los años de 1990.
}

ISSN 2174-4289 
restricción de las actividades en la denuncia contra la represión que luego se abriría a otras preocupaciones, cuando es evidente que incluso durante el período dictatorial y más aún en los inicios del gobierno constitucional hubo agrupaciones que experimentaron ampliaciones en su agenda, como pueden ser la APDH, el MEDH y Familiares, mientras que otras como el SERPAJ ya habían nacido con un abanico de preocupaciones sociales.

Como toda producción intelectual, la narrativa clásica no solo habla del objeto que analiza sino de sus propias condiciones de producción y de la histéresis de los marcos interpretativos generados en un momento histórico que ya no es el actual. Pese a ello, su profundización y complejización abrió progresivamente nuevos temas y problemas, cada vez más abordados desde criterios historiográficos en un marco de hibridación disciplinar. Sigue existiendo una radical distinción entre algunos discursos que hacen caso omiso de las variaciones regionales y postulan la identidad de su objeto de estudio con "la Argentina", o afirman su validez general incluso cuando se basan únicamente en registros capitalinos, frente a otros que enfatizan los casos locales, pero estos últimos no solo crecen sino que además obtienen una repercusión importante en el ámbito historiográfico. Los aportes de Azconegui, Kotler, Solís, Scocco, Franco, Jensen, Yankelevich y los míos propios, muestran un complejo panorama de luchas, posiciones políticas y formas de organización de las acciones, sea del interior, ${ }^{34}$ sea del exterior del Estado nacional. ${ }^{35}$ Lo cierto es que la formación de un ámbito de estudios sobre la movilización pro derechos humanos se ha enriquecido paulatinamente hasta abarcar tal multiplicidad de enfoques y recortes que es difícil predicar todavía la unidad empírica de un espacio conformado por las agrupaciones circunscritas en él -aunque sí en cambio pueda encontrarse un espacio académico dedicado a aquel-.

\footnotetext{
${ }^{34}$ Véase Luciano Alonso, Luchas en plazas vacías de sueños. Movimiento de derechos humanos, orden local y acción antisistémica en Santa Fe (Rosario: Prohistoria, 2011); y María Cecilia Azconegui, "De madres de desaparecidos a Madres de Plaza de Mayo. La definición de identidades en el seno de la Asamblea Permanente por los Derechos Humanos filial Neuquén y Alto Valle”, ponencia presentada en las XII Jornadas Interescuelas / Departamentos de Historia, San Carlos de Bariloche, 2009; e Id., "Derechos humanos, política y religión en Neuquén", ponencia presentada en las XIII Jornadas Interescuelas / Departamentos de Historia, Catamarca, 2011; Rubén Kotler, Los movimientos sociales: formas de resistencia a la dictadura. Madres de Detenidos-Desaparecidos de Tucumán (Buenos Aires: Imago Mundi / Programa de Historia Oral de la UBA, 2006), e Id., "La Asociación de Abogados por los DDHH de Tucumán. La resistencia al pasado dictatorial en los primeros años de la larga transición vigilada", ponencia presentada en las XIV Jornadas Interescuelas / Departamentos de Historia, Mendoza, 2013; Ana Carol Solís, "Las acciones pro-derechos y justicia: construyendo el marco de la impunidad, 1994-1996", Anuario de la Escuela de Historia de la UNR, 21 (2006): 221-252, e Id., "Experiencias y discursos de/sobre Derechos Humanos. (Córdoba en los años 90)", ponencia presentada en las $I V$ Jornadas de Historia Reciente, Rosario, 2008; Marianella Scocco, "El surgimiento de los organismos de Derechos Humanos en Rosario. El caso de las filiales de Madres y Abuelas de Plaza de Mayo", ponencia presentada en las XIV Jornadas Interescuelas / Departamentos de Historia, Mendoza, 2013.

${ }^{35}$ Véase Luciano Alonso, Defensa de los derechos humanos y cultura política: entre Argentina y Madrid, 1975-2005 (Santa María de La Rábida/ Sevilla: Universidad Internacional de Andalucía, 2010). Recuperado de: http://dspace.unia.es/handle/10334/187 [consulta 28 junio, 2018]; más los textos de Marina Franco, Silvina Jensen y Pablo Yankelevich anteriormente citados.
}

ISSN 2174-4289 
Si esta narrativa clásica que centraba su mirada sobre Buenos Aires $-\mathrm{y}$ los ocho organismos a los que hemos aludido- pudo enunciarse con plausibilidad, fue porque no careció de una fuerte referencialidad empírica y porque surgió en combinación con las narrativas producidas en el seno del mismo movimiento social. Probablemente, la primera narrativa que distinguió a determinadas agrupaciones surgidas a mediados de la década de 1970 de otras anteriores no sea la proveniente de los análisis académicos, sino la de esas mismas organizaciones. En el proceso de confrontación con las agencias represivas estatales, las agrupaciones que hoy consideramos parte del movimiento por los derechos humanos se desmarcaron discursivamente de los partidos políticos y las organizaciones político-militares. Su narrativa de defensa como gesto apolítico actuaba como respuesta a otra narrativa rival ya instalada en espacio público: la de la derecha, que postulaba la necesidad de imponer orden contra un enemigo interno.

Obviamente, el escenario capitalino tenía (y aún tiene) una mayor perceptibilidad social e impacto político, con lo cual la visibilidad de un conjunto de organizaciones que trabajaban por separado pero que establecían un lugar común de resistencia frente al terror de Estado solo podía afirmar la lectura académica que los percibiera como $e$ pluribus unum. Esas mismas agrupaciones llegaron durante el gobierno militar a emprender acciones coordinadas, concibiéndose a sí mismas como instancias articuladas en la defensa de los derechos humanos y presentándose en la esfera pública como prescindentes de las luchas por el poder del Estado o la conducción del gobierno. Así, esos "ocho organismos" actuaron en colaboración, comenzando a aparecer sus nombres combinados en volantes, carteles y comunicados.

Tal vez pueda postularse que esa relación entre las agrupaciones capitalinas y una narrativa académica no constituye un mero vínculo entre referente y discurso, sino un entramado de significaciones que produjo el reconocimiento de la noción de movimiento social como una interpretación válida del conjunto - conjunto del cual a su vez estaban excluidos otros agentes-. No se trata de plantear que el movimiento no pueda reconocerse como tal en prácticas sociales específicas con independencia del sentido que los propios participantes le den a la acción, pero no solamente las dos dimensiones son pertinentes para su análisis sino que a partir de cierto momento temporal, y en determinadas localizaciones, la identificación de un movimiento -el "ahí está" del investigador- pudo coincidir con la identificación del movimiento -el "aquí estamos" de sus componentes-.

Aunque quizá, la variedad de experiencias locales impida en rigor encorsetar las acciones pro derechos humanos bajo el paraguas categorial del término "movimiento social". Los estudios en curso muestran una pluralidad de agentes, de escenarios y de relaciones institucionales muy amplia, que obliga al escrutinio de la visión clásica así como a repensar las formas de identificación y reconstrucción narrativa de ese objeto en perspectiva diacrónica.

\section{A modo de conclusión: un horizonte de desafíos}


En función de lo apuntado hasta aquí, puede asumirse que pese a variados vacíos y limitaciones la práctica historiográfica conocida en Argentina como "historia reciente" ha tenido un desarrollo en los últimos años significativo. Correspondería ahora revisar la posibilidad de identificar tensiones o bloqueos que pueden estar produciéndose en su despliegue.

En primer lugar, los historiadores no descubrieron este campo de estudio. Multitud de temáticas identificadas con el pasado reciente habían ya sido abordadas con anterioridad por periodistas y científicos de las ciencias sociales, como ser sociólogos, economistas y politólogos, y -sobre todo desde mediados de la década de 1990- fueron materia de una profusa literatura testimonial que interpelaba al pasado desde las memorias sociales e individuales, fueran estas dominantes o marginales. En el caso particular de la represión, las narraciones más poderosas fueron las generadas por otros agentes sociales como los agrupamientos integrantes del movimiento de derechos humanos, las Comisiones investigadoras y los juzgados. Esa situación no obstaculizó necesariamente el desarrollo historiográfico sino que por el contrario brindó en muchas ocasiones las bases para la identificación de fuentes o la reconstrucción de procesos. En lo que respecta a la producción académica, esta coyuntura no solo permitió hibridaciones y rompió los moldes de las disciplinas, sino que más adelante desembocó en interacciones fructíferas con semiólogos, psicólogos, filósofos e investigadores del arte. Pero en el caso particular de los estudios encuadrados en las ciencias sociales se fue imponiendo el recurso a distintos conceptos, que muchas veces actuaron como categorías de análisis a menudo apriorísticas. Como resultado, el trabajo empírico de los historiadores se percibía como superfluo y redundante allí donde ya aparecían definidos determinados procesos o agentes, o falto de sustento teórico cuando no se articulaba con un debate terminológico previo.

En segundo término la construcción de narrativas sobre el pasado reciente, tanto en el campo académico en general como en el historiográfico en particular, adoleció del acusado centralismo propio de la estructuración espacial argentina. Quizá se trate del sino de cualquier país con una poderosa capitalidad y un interior muy diferenciado, pero es notorio que casi con referencia a cualquier problema historiográfico, la historia de una parte -de la región capitalina- del Estado nacional pasa por ser la historia nacional, hasta que surgen nuevas historias consideradas -estas sí- "regionales". Es obvio que la centralidad política y cultural de la ciudad de Buenos Aires no puede ser desconocida a la hora de definir una mirada holística sobre cualquier objeto historiográfico, pero la caracterización de sus peculiaridades locales no puede reemplazar el cotejo con otras experiencias ni resultar la única clave explicativa del conjunto.

Tercero, como se ha visto la historia reciente nació como respuesta al silencio de las corrientes historiográficas e instituciones académicas dominantes con respecto al período de violencias políticas y sociales que precedió a la supuesta "restauración democrática", proceso de emergencia en el que la investigación quedó en gran medida atada a las temáticas que había pretendido visibilizar. El texto antes referido de Franco y Levín demuestra cómo quienes hemos asumido esta especialidad hemos asumido 
también dicha limitación. Como muestra de un consenso extendido, la mayor parte de los aportes a ese volumen miraban el pasado en clave de conflictos, silencios, violencias, peticiones de justicia, desplazamientos; en suma: componentes o síntomas del trauma, y en ese sentido retornaban una y otra vez al caso de la última dictadura militar argentina. En rigor esto tampoco fue un problema para muchos de quienes investigamos este campo, pues condujo al análisis conjunto de las variables académicas y de las ético-políticas. Pero extrapolando esa definición a los desarrollos posteriores y más generales, se ha producido una suerte de cierre temático de la especialidad que hace dificultoso dialogar o integrar a aquellos estudios que no solo tratan de materias relativas al tiempo reciente, sino incluso a los que bucean en los conflictos de la etapa constitucional coetánea que no se derivan de los problemas aludidos. Por todo ello, quienes explícitamente hacemos historia reciente tenemos una marcada tendencia a trabajar con el período de conflictos de los años de 1960-70 como matriz de nuestras lecturas, mientras quienes se han centrado en temas más inmediatos suelen no pensar en la historia reciente como marco de sus enfoques, aún cuando muchas veces compartamos métodos o referencias teóricas.

Por último, al recurrir a un término que hace a la definición cronológica respecto del presente -sin establecer otros parámetros como la implicación generacional o su impacto en la actualidad- la misma delimitación de lo que se entiende incurso en la historia reciente se torna en parte confusa. Las convocatorias de las Jornadas de Trabajo sobre Historia Reciente son un buen ejemplo de ello, al afirmarse en sus circulares que: "Aunque la delimitación cronológica de la Historia Reciente es objeto de discusiones y polémicas, por razones organizativas sólo se recibirán ponencias referidas a períodos posteriores al año $1955 . . .36$ Al tomar como punto de partida el incremento de la violencia política abierto con el derrocamiento del segundo gobierno de Perón, las Jornadas asumen una definición de su propio objeto en orden a los planteamientos realizados en la observación anterior, pero además ponen un listón temporal difícil. ¿Qué tan reciente es el año 1955 para la mayoría de los participantes de esos encuentros, que ni siquiera habíamos nacido para entonces? Si se supone que el carácter de "reciente" lo da su aplicación a la actualidad de generaciones presentes, debería al menos concederse que para muchos temas la implicación puede venir de mucho más atrás. Por ejemplo, para las comunidades indígenas la conquista de las llanuras pampeana y chaqueña o de la región patagónica entre el siglo XIX e inicios del XX es mucho más condicionante de cara a sus realidades actuales que la confrontación entre peronistas y antiperonistas en cualquier momento de los últimos sesenta años. Por el contrario, la definición de los conflictos y las luchas del presente puede pasar para muchos jóvenes por fenómenos más cercanos que una matriz histórica que se les semeja ya lejana.

\footnotetext{
${ }^{36}$ En tanto participo personalmente del comité organizador de esas jornadas, que van camino a su séptima edición bianual, asumo plenamente las limitaciones de esa formulación, adoptada como modo de cortar el nudo gordiano de un concepto tan poco apropiado. La frase citada puede encontrarse en varias circulares e incluso en la convocatoria a las VII Jornadas a realizarse en La Plata en agosto de 2014.

ISSN 2174-4289 
Con todos esos inconvenientes, la Historia reciente crece y se afirma en Argentina, acompañada por profundos debates de carácter ético-político sobre la violencia insurgente, la calificación de los crímenes de Estado, la trasposición de conceptos jurídicos o sociológicos y la interlocución con diversos actores sociales. Quizá esas cuestiones no constituyan en sí problemas, sino mejor incentivos y posibilidades para una superación constante. Es posible incluso pensar en un escenario de hibridación disciplinar en el cual los historiadores han logrado poner en discusión la necesidad de una mirada atenta a la dimensión diacrónica y a las diferenciaciones entre dimensiones, niveles y formas más allá del reconocimiento de matrices generales.

Pero sobre todo, la fijación de la Historia reciente en todos aquellos aspectos que puedan ser pensados desde el período de movilizaciones sociales y represiones sangrientas por el cual pasó Argentina, ha acentuado su carácter político con respecto a otras formas de hacer historia. Ello, en vez de resultar un inconveniente puede ser un acicate en pos de la auto-clarificación de la labor historiográfica y la denuncia de los modos en los cuales las representaciones del pasado pueden reproducir las dominaciones del presente. Por más que necesite proyectarse hacia los años más inmediatos a nuestro momento actual, la historia reciente es un laboratorio de primer orden para poner en cuestión las relaciones entre las implicaciones subjetivas, la dimensión política y el trabajo disciplinar. Ampliando su horizonte temático a las luchas y desafíos sociales de la pos-dictadura, enfatizando su carácter de lugar de conjunción de múltiples disciplinas científicas, preocupándose por todas las formas de dominación y resistencia y no solo por las predicables de los regímenes autoritarios, analizando los procesos de cambio social y haciendo foco en las inscripciones locales de los conflictos con sus recurrencias y diversidades, la historia reciente puede no solo superar sus propios obstáculos sino además reavivar con un sentido crítico el carácter de apuesta ético-política que marcó su emergencia.

Y en ese camino la historia reciente puede asumir la revisión de las luchas, las dominaciones y las resistencias del período de violencias que acompañó su nacimiento como algo más que un objeto historiográfico. Tal vez pueda convocar esos análisis y consolidar las memorias sociales sobre ellos, para enfrentar nuestros presentes condicionados así como los futuros que nos acechan. Como lo plantearan Oberti y Pittaluga en un texto de lectura imprescindible para asomarse a las relaciones entre memoria, historia y representaciones de las militancias en la historia argentina reciente: "No se trata tan solo de explicitar un compromiso político personal con la historia reciente de este país... sino también de desplegar un trabajo crítico que por ello sea capaz de abrir los pasados hasta ahora olvidados". 37

\footnotetext{
${ }^{37}$ Alejandra Oberti y Roberto Pittaluga, Memorias en montaje. Escrituras de la militancia y pensamientos sobre la historia (Santa Fe: María Muratore, 2012), 22.

ISSN 2174-4289 


\section{Profile}

Luciano Alonso es graduado en Historia, magister en Historia Latinoamericana y en Ciencias Sociales con orientación en Sociología Política, y Doctor en Historia. Actualmente es Profesor Asociado Ordinario en las Universidades Nacionales del Litoral y Rosario (Argentina), en las cátedras de Historia Social y Teoría Social, y director del Centro de Estudios Sociales Interdisciplinarios del Litoral (CESIL) de la Universidad Nacional del Litoral. En los últimos años ha desarrollado estudios sobre movilización pro-derechos humanos y violencia política desde los años de 1970 a la actualidad.

Luciano Alonso graduated in History, has a master in Latin-American History and Social Sciences oriented to Political Sociology, and a PhD in History. He currently works as Associate Professor in the National Universities of Litoral and Rosario (Argentina), in the chairs of Social History and Social Theory, and runs the Centre of Social Interdisciplinary Studies of the Litoral (CESIL) in the National University of the Litoral. In recent times he has undertaken studies on the mobilizations pro-human rights and political violence from the 1970s to nowadays.

Fecha de recepción: 15 de mayo de 2018.

Fecha de aceptación: 4 de junio de 2018.

Publicación: 30 de junio de 2018. 